\title{
Sob suspeita: o controle dos clubes esportivos no contexto colonial português
}

Victor Andrade de $\mathrm{Melo}^{3}$

\section{Marcelo Bittencourt ${ }^{4}$}

Esse artigo tem por objetivo discutir as ações de controle do funcionamento de clubes esportivos desencadeadas pelos órgãos portugueses de segurança tanto em território europeu quanto nas colônias africanas de Angola e Cabo Verde entre as décadas de 1940 e 1960. O intuito é lançar um novo olhar sobre o conjunto de embates que marcaram o contexto colonial, prospectando estratégias de luta menos consideradas nas análises acadêmicas desses conflitos.

Palavras-chave: Esporte, política, lutas coloniais.

\section{Under suspicion: the control of the sports clubs in the Portuguese colonial context}

The aim of this paper is to discuss actions undertaken by Portuguese security authorities to control activities of sports clubs in their own national territory as well as in their African colonies: Angola and Cape Verde between 1940 and 1960 decades. Focusing least

1 Este artigo é um dos resultados do projeto "Esporte, Colonialismo e Pós-Colonialismo nos Países Africanos de Língua Oficial Portuguesa", desenvolvido com recursos do Conselho Nacional de Desenvolvimento Científico e Tecnológico (Edital nº 18/2007/CPLP, Edital nº 13/2008/CPLP, Edital $\left.n^{\circ} 37 / 2010 / C P L P\right)$. Pelas contribuições a este texto, agradecemos também ao professor doutor Augusto Nascimento, do Instituto de Investigação Científica Tropical/Portugal.

2 Artigo recebido em 15.2.2012 e aprovado para publicação em 20.5.2012.

3 Professor associado da Universidade Federal do Rio de Janeiro.E-mail: victor.a.melo@uol.com.br

4 Professor adjunto do Departamento de História da Universidade Federal Fluminense. E-mail: marcelo216@gmail.com 
studied strategies of resistance, the paper seeks to develop a new approach to understand colonial clashes.

Keywords: Sport, politics, colonial clashes.

Sous soupçon: le contrôle des clubs sportifs dans le contexte colonial portugais Cet article vise à discuter des mesures pour contrôler le fonctionnement des clubs sportifs déclenchées par les agences de sécurité portugaise à la fois sur le territoire européen et dans les colonies africaines: Angola et Cap-Vert entre 1940 et 1960 des décennies. L'intention est de lancer un nouveau regard sur l'ensemble des conflits que caractérisent le contexte colonial pour prospecter des stratégies de lutte usuellement ignorées par les analyses académiques.

Mots-clés: Sport, politique, lutte coloniale.

\section{Introdução}

Após a Segunda Grande Guerra, várias colônias europeias na África entabularam processos de rompimento com suas respectivas metrópoles. Se a princípio era forte agente motivador o ideal pan-africano, na década de 1950 ganharam consistência propostas de caráter nacional, construídas no âmbito das fronteiras traçadas pelo colonialismo.

Naquele contexto, diferentemente de outras metrópoles europeias, Portugal rejeitava peremptoriamente a possibilidade de rompimento dos laços coloniais, negando-se a promover a autonomia jurídica de seus territórios nos continentes africano e asiático. Tal atitude tinha relação, por um lado, com a importância da representação de império na construção da ideia de nação portuguesa. Por outro lado, o projeto político do Estado Novo mantinha conexões tão estreitas com o colonialismo que o fim do segundo parecia ameaçar inexoravelmente o primeiro. ${ }^{5}$

5 Para mais informações, ver ANTUNES, José Freire. O império com pés de barro. Colonização e descolonização: as ideologias em Portugal. Lisboa: Dom Quixote, 1980; CABAÇO, José Luís. Moçambique: identidade, colonialismo e libertação. São Paulo: Unesp, 2009; PIMENTA, Fernando Tavares. Portugal e o século XX: Estado-Império e descolonização (1890-1975). Lisboa: Afrontamento, 2010. 
Dada essa postura intransigente, o governo português sofreu pressões diversas de organismos internacionais. A Organização das Nações Unidas, por exemplo, só aceitou o ingresso de Portugal como país-membro em 1955. Buscando responder a tais demandas, os ideólogos do Estado Novo, promovendo uma leitura das teorias lusotropicalistas de Gilberto Freyre, defendiam a peculiaridade da colonização portuguesa, supostamente responsável pela construção de sociedades multirraciais. ${ }^{6}$ Esse discurso logrou certa repercussão e alguma eficácia no cenário internacional, afetando até mesmo algumas lideranças nacionalistas de outras colônias africanas em sua relação com os movimentos independentistas que se voltavam contra o domínio português.

Tal uso do discurso lusotropicalista tinha, evidentemente, estreita relação com o projeto português de manutenção de suas colônias. A revogação, em 1951, do Ato Colonial, um dos sustentáculos da política salazarista, e a transformação das colônias em províncias ultramarinas podem ser entendidas, portanto, como uma estratégia de ajuste retórico que reforçava a falsa ideia de um "colonialismo diferente".

Ainda que tenham sido encaminhadas algumas propostas de distensão, expressas, por exemplo, em certas posições e ações de Adriano Moreira e mesmo de Marcelo Caetano, essas iniciativas não foram avante ou tiveram alcance limitado, esbarrando nos limites da relação colonial. ${ }^{7}$

Nesse quadro, os territórios de Portugal na África entraram em ebulição: fortaleceram-se os movimentos anticoloniais e, na década de 1960, conflitos armados foram desencadeados em Angola, Guiné-Bissau e Moçambique. Cabo Verde e São Tomé e Príncipe também sentiriam os desdobramentos desse novo contexto, mesmo que não tenham ocorrido embates bélicos em seus limites.

6 Para mais informações sobre a proximidade entre Gilberto Freyre e o salazarismo, ver CASTELO, Claudia. O modo português de estar no mundo. O luso-tropicalismo e a ideologia colonial portuguesa, 1933-1961. Porto: Afrontamento, 1998.

7 Para mais informações, ver CABAÇO. Op. cit.; e PIMENTA. Op. cit. 
Que papel terá desempenhado o esporte nesse cenário? Estudos como os de Ranger, ${ }^{8}$ Martin, ${ }^{9}$ Fair, ${ }^{10}$ Giullianotti ${ }^{11}$ e Vidacs ${ }^{12}$ demonstram que, no continente africano, se, de um lado, a prática esportiva foi utilizada por regimes coloniais como ferramenta de diferenciação social e de disciplinarização dos nativos, de outro, foi apreendida por líderes e militantes das lutas anticoloniais como alternativa para expressar discordâncias com o poder constituído, dadas sua visibilidade e capacidade de aglutinar, ao mesmo tempo que parecia menos suspeita, por não pertencer ao grupo das óbvias atividades políticas.

O envolvimento de líderes e militantes de movimentos de contestação com o esporte pode também ser encontrado nas colônias portuguesas, como demonstram os estudos de Bittencourt, ${ }^{13}$ Domingos ${ }^{14}$ e Melo. ${ }^{15}$ De fato, com o acirrar das tensões coloniais, o governo metropolitano, percebendo que não eram tão alheias à política, ampliou suas iniciativas de controle do funcionamento das agremiações esportivas e culturais em geral, algo de diferentes formas já existente em períodos anteriores.

8 RANGER, Terence. Pugilism and pathology: African boxing and the Black urban experience in Southern Rhodesia. In: BAKER, William J.; Mangan, James A. (Eds.). Sport in Africa: essays in social history. Nova York: African Publishing Company, 1987. p. 196-213.

9 MARTIN, Phyllis M. Leisure and society in colonial Brazzaville. Cambridge: Cambridge University Press, 1995.

10 FAIR, Laura. Ngoma reverberations: Swalihi music culture and the making of the football aesthetics in early twentieth century Zanzibar. In: ARMSTRONG, Gary; GIULIANOTTI, Richard (Eds.). Football in Africa: conflict, conciliation and community. Nova York: Palgrave Macmillan, 2004. p. 103-113.

11 GIULIANOTTI, Richard. Os estudos do esporte no continente africano. In: MELO, Victor Andrade de; BITTENCOURT, Marcelo; NASCIMENTO, Augusto (Orgs.). Mais do que um jogo: o esporte no continente africano. Rio de Janeiro: Apicuri, 2010. p. 13-36.

12 VIDACS, Bea. O esporte e os estudos africanos. In: MELO, Victor Andrade de; BITTENCOURT, Marcelo; NASCIMENTO, Augusto (Orgs.). Mais do que um jogo: o esporte no continente africano. Rio de Janeiro: Apicuri, 2010. p. 37-70.

13 BITTENCOURT, Marcelo. Dos jornais às armas. Trajectórias da contestação angolana. Lisboa: Vega, 1999; BITTENCOURT, Marcelo. Jogando no campo do inimigo: futebol e política em Angola. In: MELO, Victor Andrade de; BITTENCOURT, Marcelo; NASCIMENTO, Augusto (Orgs.). Mais do que um jogo: o esporte no continente africano. Rio de Janeiro: Apicuri, 2010. p. 101-132.

14 DOMINGOS, Nuno. Futebol e colonialismo, dominação e apropriação: sobre o caso moçambicano. Análise Social, Lisboa, v. XLI, n. 179, p. 397-416, 2006.

15 MELO, Victor Andrade de. Jogos de identidade: o esporte em Cabo Verde. Rio de Janeiro: Apicuri, 2011. 
Este artigo tem por objetivo discutir tais ações, desencadeadas pelos órgãos portugueses de segurança tanto em território europeu, como no caso das investigações relacionadas com o Clube Marítimo Africano, quanto nas colônias africanas, como no que se refere a algumas iniciativas relativas a clubes de Angola e Cabo Verde.

Nosso intuito é lançar um novo olhar sobre o conjunto de embates que marcaram o contexto colonial, prospectando estratégias de luta menos consideradas nas análises acadêmicas desses conflitos.

\section{Conexão nativista: o Clube Marítimo Africano}

O Clube Marítimo Africano (CMA) foi fundado em Lisboa, em 1954, por trabalhadores de origem africana que atuavam na Marinha Mercante portuguesa e por membros da Casa dos Estudantes do Império (CEI).

Os estudantes da CEI já tinham em conta as experiências entabuladas nessa instituição, criada, em 1944, com o apoio do governo português, com o intuito de ajudar e, em boa medida, também controlar os originários das colônias/províncias portuguesas que vinham dar continuidade a suas formações escolares na metrópole. As iniciativas relacionadas com o esporte desempenharam um importante papel na Casa.

Faria informa que já no primeiro ano de funcionamento organizaram-se na Casa "campeonatos de pingue-pongue, futebol e hóquei em patins". ${ }^{16} \mathrm{Com}$ o decorrer do tempo, constantemente foram promovidos torneios internos de diversas modalidades, ocasiões de integração muito aguardadas e apreciadas pelos estudantes.

Além disso, equipes da Casa com frequência participavam de competições esportivas externas. Por exemplo, em 1948, celebra Arnaldo Figueira, um dos presidentes da instituição: "O desporto tem tomado grande incremento nesses últimos tempos, estando a interessar vivamente o torneio de futebol, organizado pelo Ateneu Comercial de Lisboa e o Club Internacional de Futebol, em que participa a equipe da CEI, que tem alcançado brilhantes resultados." ${ }^{17}$

16 FARIA, Antônio. A Casa dos Estudantes do Império: itinerário histórico. Lisboa: Câmara Municipal de Lisboa, 1995. p. 15.

17 In: AMARÍLIS, Orlanda; FERREIRA, Manuel (Orgs.). Mensagem - Boletim da Casa dos Estudantes do Império - coletânea de todos os números. Lousa: Alalc, 1996. p. 21. 
Essas ocasiões contribuíam para dar maior visibilidade a esses jovens no cenário metropolitano, gestando uma alternativa de promoção de alguma integração, tanto entre os estudantes quanto destes com a população. Podemos perceber a celebração dessa possibilidade nos comentários sobre a participação de uma equipe da Casa na "Taça A Bola", realizada em 1948: "Em boa hora nos inscrevemos neste torneio, porque ele tem contribuído não só para demonstrar a boa categoria e correção de nossos jogadores, mas também para unir ainda mais a nossa massa associativa que no decorrer do Torneio só tem tido um pensamento: a vitória da CEI."18

Importa destacar que a Casa reunia estudantes com diferentes e até divergentes histórias de vida e projetos políticos, de indivíduos mais próximos ao regime até os que o desafiaram com armas na mão. É a partir dessa advertência que devemos perceber na CEI a coexistência de uma perspectiva integracionista com o fato de ter-se transformado em uma das sedes do desenvolvimento de um pensamento anticolonial, local de conscientização política que induziu a emergência e consolidação de importantes lideranças, como Amílcar Cabral, Agostinho Neto, Lúcio Lara, Marcelino dos Santos, entre outros. Contudo, a instituição guardava uma série de limites, inclusive porque o governo metropolitano estava sempre atento às ações de seus membros. ${ }^{19}$

A própria ligação entre alguns membros da CEI e a oposição portuguesa chamaria a atenção da Pide. ${ }^{20}$ De fato, como lembra João Vieira Lopes, as primeiras prisões de nacionalistas africanos das colônias portuguesas na metrópole ocorreram por sua proximidade das organizações antissalazaristas:

Eu saí de Angola para fazer os meus estudos superiores em abril de 1952 [...] e fui alistado na Casa dos Estudantes do Império, de Coimbra. [...] Aí foram os meus primeiros contatos. [...] a nossa atividade na Casa dos Estudantes era uma atividade que, sem ser essencialmente política, no fundo, tinha sempre, em todas as nossas ações, atividades, um substrato político. A polícia política, aliás, andava em cima da

18 Ibid., p. 26.

19 Para mais informações sobre a CEI, ver BITTENCOURT. Op. cit., 1999; FARIA. Op. cit., 1995; e FARIA, Antônio. Linha estreita de liberdade: a Casa dos Estudantes do Império. Lisboa: Colibri, 1997.

20 Substituindo a Polícia de Vigilância e Defesa do Estado (PVDE), a Polícia Internacional e de Defesa do Estado (PIDE) funcionou de 1945 a 1969. Com as mudanças no quadro político português, desencadeadas com o afastamento de Salazar, por problemas médicos, e a assunção de Marcelo Caetano à presidência do Conselho de Ministros, passou a se chamar Direção Geral da Segurança (DGS). 
Casa dos Estudantes. E foi em Coimbra que eu conheci a prisão pela Pide em 1956, porque nessa altura já estava integrado na organização do MUD Juvenil. [...] Dois anos depois, me transfiro para Lisboa e novamente me filio na Casa dos Estudantes do Império, onde em 58 sou eleito presidente da Casa dos Estudantes do Império. ${ }^{21}$

Se a ideia de criação do CMA parece ter surgido inicialmente entre os marítimos, que procuraram alguns estudantes para ajudar na oficialização da iniciativa (os primeiros movimentos ocorreram em 1952), para os que eram da CEI havia uma boa razão para se envolverem com a agremiação: lá não haveria filhos de colonos e de funcionários da administração colonial dispostos a vigiar suas ações e defender o regime. A conformação do clube poderia, perspectivava-se, de múltiplas formas contribuir para o processo de preparação das lutas anticoloniais, sem levantar tantas suspeitas.

Nos estatutos do CMA informava-se, em seu artigo $1^{\circ}$, que se tratava de uma "agremiação desportiva dos marítimos africanos e dos africanos em geral residentes na metrópole"; em seu artigo 30, apresentava-se o intuito de "promover a educação física e a prática de desportos entre seus associados, proporcionando-lhes também meios de recreio e de cultura", explicitando-se também que "são vedadas quaisquer atividades ou participação em manifestações de caráter político e religioso". Todavia, de fato:

O Clube Marítimo Africano mantinha uma fachada lúdica e desportiva, que encobria uma grande atividade política, espalhando as ideias nacionalistas provenientes de Luanda e Bissau e constituindo, como foi a Casa dos Estudantes do Império, mais uma onda na tumultuosa maré nacionalista. ${ }^{22}$

A articulação entre marítimos e estudantes acabaria sendo estratégica no sentido de garantir o trânsito de informações entre os movimentos de contestação em organização nas colônias/províncias e na metrópole: "Embora discreto, o Clube Marítimo Africano [...] cumpriu um papel da maior relevância histórica em prol da independência das colônias portuguesas em África." ${ }^{23}$

21 Entrevista de João Vieira Lopes, concedida a Marcelo Bittencourt, realizada em Luanda, em 27 de fevereiro de 1995.

22 ROCHA, Edmundo. O Clube Marítimo Africano. Uma contribuição para a luta e independência nacional dos países sob domínio colonial português. Lisboa: Biblioteca do Museu da República e Resistência, 1998. p. 25.

23 ZAU, Filipe. Marítimos africanos e um clube com história. Lisboa: Paralelo, 2007. p. 91. 
A alternativa aos marítimos, no estabelecimento desses contatos entre militantes nativistas na metrópole e nas colônias, seria bem menos sistemática; um eventual funcionário colonial simpático às ideias independentistas dos estudantes ou situações ocasionais, como a narrada por Daniel Chipenda, com a particularidade de nesse caso ter sido o futebol, mais especificamente a excursão de um time que vinha da metrópole, o agente principal:

Eu entrei na luta política mais concretamente e diretamente em 1960, porque eu em 59 vim a Luanda. Vim a Luanda integrado na equipa da Associação Acadêmica de Coimbra [...]. E é precisamente em Luanda, numa tarde [em] que eu fui convidado a almoçar em casa da tia Tereza de Carvalho, onde depois tive uma reunião em casa do mais velho Veríssimo Costa, o pai do Desidério, e do velho Mingas. Esses dois mais velhos disseram precisamente que eles estavam a trabalhar [...], que devíamos nos preparar porque a movimentação que se estava fazendo aqui estava a ganhar forma e consistência e que nós iríamos ser chamados para participar nesta luta. ${ }^{24}$

Com o decorrer do tempo, até as conexões por meio dos marítimos tornaram-se mais difíceis. Os navios passaram a ser mais policiados, especialmente depois que membros do CMA conseguiram enviar para Angola uma máquina policopiadora, que foi muito útil entre grupos de contestação. Esse episódio ganha um colorido especial nas palavras de Lúcio Lara, que, além de realçar a importância do clube, reforça a existência de interesses diversos na agremiação:

Nós nessa altura já nos tínhamos organizado em Portugal como estudantes e marítimos. [...] Nós também organizamos o Clube Marítimo Africano, que era dos marítimos, mas onde nós - quer o Neto, quer eu, quer mais outros camaradas - estávamos na direção desse clube, aliás muito suspeito. [...] A Pide não entendia bem e andou a perguntar por que nós estávamos naquele clube se nós éramos estudantes. [...] Por acaso, eu não fui aborrecido com isso, mas o Neto, o Humberto Machado e outros [foram] [...]. Mas [o clube] era muito popular porque o angolano está sempre na farra $[\mathrm{e}]$ tínhamos farra todas as semanas, para nós a farra era o ponto de encontro entre os marítimos que traziam as notícias daqui e traziam por exemplo os pedidos, [como o de] uma máquina copiadora [que] nós os estudantes arranjamos, alguns de nós tinham relações até com os comunistas e conseguimos arranjar. [...] Essa máquina [...] teve que ir ao Lobito primeiro, não desembarcou em Luanda por causa da Pide, e do Lobito veio para cá por terra. ${ }^{25}$

24 Entrevista de Daniel Chipenda, concedida na Rádio Nacional de Angola ao programa Foi há 20 anos, realizada em 17 de junho de 1995.

25 Entrevista de Lúcio Lara, concedida a Marcelo Bittencourt, realizada em Luanda, em 7 de fevereiro de 1995. 
No Arquivo Nacional da Torre do Tombo (ANTT), em Lisboa, no fundo da Pide/DGS, é possível observar vários informes de busca e apreensão, bem como informações sobre agentes policiais que passaram a se infiltrar nas embarcações para identificar ligações "subversivas" entre a metrópole e as colônias.

Enquanto isso ocorria, o CMA, que inicialmente se instalou na casa de Humberto Machado e depois teve várias sedes espalhadas por Lisboa, promovia com constância bailes, concursos de dança, piqueniques; oferecia algum apoio na área da saúde e aulas de alfabetização; dinamizava as práticas esportivas, especialmente o futebol, no qual o clube foi muito ativo e muitas vezes vitorioso em diferentes competições.

Com intuitos múltiplos, o clube congregava pessoas com interesses diversos. José Baçanza Tomo lembra que:

Nos bailes que organizávamos, enquanto que Agostino Neto, Eduardo Mondlane, Amilcar Cabral, Humberto Machado e outros ficavam num quarto a fazer as suas reuniões, nós na sala ficávamos a dançar, mas sabíamos o que se estava a passar lá dentro com eles. Era uma forma de desviar as atenções da Pide. ${ }^{26}$

Enquanto alguns sócios, como João de Deus Telvino, que organizava as atividades de futebol, pareciam mais interessados de fato nas atividades recreativas, outros tinham interesse prioritário pelas questões políticas. De toda forma, nesse cenário, alguns começaram a tomar maior consciência das lutas anticoloniais, passando a se engajar mais diretamente nas ações de contestação. Para Fernando da Costa Campos: "Politicamente, nós aos poucos íamos trabalhando a mentalidade dos marítimos, [...] nem todos estavam integrados ao nosso problema [...], mas aos poucos nós íamos dando a volta à sua mentalidade." ${ }^{27} \mathrm{Na}$ verdade, muitos relatos sugerem a existência de uma relação anterior à formação do CMA entre alguns marítimos e o movimento nativista, como é o caso de Zito Van Dunem e Francisco Jack.

O clube era também uma possibilidade de gerar alternativas de sociabilidade para negros e mestiços em um ambiente social preconceituoso, como era o de Lisboa à época. Podemos ver algo dessa dimensão no Ofício no 1.167 , de 29 de

26 Apud ZAU. Op. cit., p. 131.

27 Apud Ibid., p. 145. 
setembro de 1959, de Jacinto Corvo, agente da Pide de Setúbal. ${ }^{28}$ Descrevendo um piquenique realizado em Feijó-Cova da Piedade, ele informa que 15 casais, com seus filhos, estiveram presentes. Segundo seu olhar:

Não se constatou a interferência ou contato com qualquer continental, pois, segundo consta no local, onde é hábito reunirem várias vezes, não gostam do convívio dos brancos, naquelas reuniões. Por nada de suspeito se ter constatado, tudo leva a crer que o piquenique em referência, se algo tem relação com a política, deve tratar-se de questão racial.

Para além da incapacidade do agente de observar a provável demarcação imposta pelos brancos ao grupo, vale destacar a diversidade de ações promovidas pelo CMA e sua preocupação em ampliar o recrutamento de sócios, envolvendo até mesmo as famílias. Edmundo Rocha ${ }^{29}$ lembra que também a comunidade africana protestante, quase sempre vinculada a outros circuitos sociais que não a CEI, mantinha ligações com o clube.

As ações do Marítimo pareciam ser inspiradas e ter conexão direta com a experiência da Liga Nacional Africana (LNA), agremiação angolana criada em 1930, com caráter assistencial, cultural e esportivo. A LNA chegou a receber apoios diretos do governo colonial, mas, no decorrer da década de 1950, a Pide percebeu que muitos de seus membros estavam envolvidos com movimentos nativistas e grupos de contestação. ${ }^{30}$

É fato que alguns diretores da Liga estavam envolvidos com iniciativas anticoloniais: Jaime de Araujo, cônego Manuel Mendes das Neves, André Rodrigues Mingas Junior, João Van Dunem, Idílio Machado, entre outros. Em ofício de 20 de setembro de 1956, ${ }^{31}$ o tenente Sebastião Artur Ribeiro Galvão, da Polícia de Segurança Pública (PSP) de Luanda, em resposta ao pedido de informação da Pide de Lisboa, datado de 6 de junho de 1956, chegou a afirmar que todos os membros da diretoria da LNA “são suspeitos de separatistas", e que aquela associação:

28 ANTT, PIDE/DGS, Serviços Centrais, Proc. n 2.668/1954, Clube Marítimo Africano, fl. 698.

29 Op. cit., p. 25.

30 Bittencourt (Op. cit., 1999) mostra que, em muitas agremiações angolanas, entre as quais a LNA, surgiram grupos mais radicais, normalmente formados pelos mais jovens; muitos desses depois se envolveriam mais diretamente nas lutas coloniais.

31 ANTT, PIDE/DGS, Serviços Centrais, Proc. nº 2.668/1954, Clube Marítimo Africano, fls. 614-618. 
Não tem correspondido satisfatoriamente aos fins para que foi criada e está referenciada nessa polícia como centro de propaganda separatista.

Desde a sua fundação e através de seus dirigentes e associados teve sempre procedimento de aparente fidelidade e obediência ao governo, no entanto, vem-se notando que o seu fim principal é a separação da mãe-pátria, para o que tem muito contribuído os acontecimentos registrados na África do Norte.

Vale destacar que João Van Dunem, André Mingas e Idílio Machado tinham relações familiares e políticas com Zito Van Dunem, Rui Mingas e Humberto Machado, sócios e dirigentes do CMA.

A relação entre as agremiações foi aventada pela Pide já na primeira vez que o clube de Lisboa foi investigado, ainda no ano 1954, em função de uma minuciosa denúncia de Serafina de Assis, ex-namorada de Agostinho Neto. ${ }^{32}$

$\mathrm{Na}$ carta, ela informava que Neto, que segundo seu olhar teria "ideologias avançadas", estava envolvido, junto com Humberto Machado e Júlia Machado, com a criação de um clube. O primeiro impulso, dizia, era fundar uma associação assistencial exclusiva para marítimos; somente depois teria surgido a ideia de criar uma seção esportiva, tendo havido debates sobre sua pertinência (chegou-se a pensar na fundação do Grupo Desportivo do Ultramar). Por fim, decidiu-se que seria uma única agremiação de caráter cultural, esportivo e assistencial. A finalidade real, contudo, alertava Serafina, era a propaganda antinacionalista.

A carta informava ainda que se chegou a pensar em só se aceitar na agremiação "indivíduos de cor", o que ao fim foi desconsiderado. A acreditar em algo do teor informado, mesmo reconhecendo que é comum haver exageros em denúncias desse tipo, percebe-se que fora bem planejada a fundação do CMA, com o intuito de ser um espaço menos vulnerável aos olhares da Pide.

Em resposta à denúncia, investigadores foram à sede do clube, na época a residência de Humberto Machado, recolheram muito material considerado "suspeito" (algumas coisas que realmente demonstravam algum grau de ligação com as turbulências em Angola, mas outras mais inocentes, como cartões-postais) e o convocaram a prestar depoimento. No Auto de Declarações, lavrado em 9 de junho de $1954,{ }^{33}$ temos acesso à íntegra das desconfianças do órgão policial e às posições do depoente investigado, que, em resumo, informa que:

32 ANTT, PIDE/DGS, Serviços Centrais, Proc. n 2.668/1954, Clube Marítimo Africano, fls. 646-647. 33 ANTT, PIDE/DGS, Serviços Centrais, Proc. $n^{\circ}$ 2.668/1954, Clube Marítimo Africano, fls. 634-636. 
O CMA está em organização. Há cerca de um ano uns marítimos africanos realizaram um desafio de futebol em Lisboa e daí veio-lhes o desejo de terem um clube próprio. Como o declarante conhece muitos marítimos, pediram sua colaboração [...]. O Clube destina-se a desporto e recreio. Que até a presente data foram organizadas cerca de quatro festas.

A forma de organização da agremiação parecia confundir alguns agentes da Pide. Vejamos que em um relatório datado de 9 de fevereiro de 1955 assevera-se que a iniciativa só tinha mesmo fins não políticos:

O Clube Marítimo Africano, ainda sem sede, foi fundado por Humberto Machado [...] e Raul Francisco Caterça. Aqueles indivíduos fundaram esse clube com o fim de reunirem todas as pessoas oriundas das nossas províncias africanas, que se encontram a viver nesta cidade de Lisboa, bem como suas famílias, tendo em vista arranjarem casa própria a fim de darem bailes; é por conseguinte um clube somente recreativo. ${ }^{34}$

No ano 1958, contudo, a Pide recebe outra denúncia anônima:

tem esta o fim de lhe participar que na Rua Leite Vasconcelos, 82 - cave esquerdo e direito, existem umas determinadas pessoas, que falam contra a situação e fazem comitês com homens de cor, até altas horas da noite, à porta fechada, tendo envolvido em grande barulhada, não só na residência indicada, como também num Clube que tem por nome de Clube Marítimo Africano [...]. Era bom que mandasse investigar como mesmo prender certo pessoal que ali habita. ${ }^{35}$

A Pide envia o agente Lourenço para investigar "quem são os indivíduos que falam contra o governo na Rua Leite de Vasconcelos, n. 82, e bem se ali está instalado o Clube Marítimo [...]. Procure averiguar quais são as frases proferidas contra o governo e se possível fazer a prova". ${ }^{36}$

$\mathrm{O}$ investigador informa que o clube não estava instalado no endereço citado, no qual se encontrava, na verdade, a residência de Humberto Machado, que frequentemente reunia "pessoas de cor" a título de assistencialismo, promovendo jantares para os que tinham dificuldades financeiras. Para ele, as reuniões se estendiam até tarde, mas não incomodavam a vizinhança. Por fim, conclui: "segundo me informaram, nada tendo a ver com política. Isto não quer dizer que

34 Apud ZAU. Op. cit., p. 85.

35 Apud Ibid., p. 87.

36 ANTT, PIDE/DGS, Serviços Centrais, Proc. n 2.668/1954, Clube Marítimo Africano, fl. 598. Relatório $\mathrm{n}^{\circ} 1.342$, de 6 de agosto de 1958. 
alguns dos que tomavam parte em tais reuniões não fossem contrários a atual situação, mas a sua finalidade não era essa”.

Mais ainda, Lourenço encheu de elogios Humberto Machado, considerando-o um pacato trabalhador: "politicamente, [...] é elemento afeto ao atual regime, nada me constando também em desabono de sua esposa”. Não surpreende que haja no documento uma marca de lápis vermelho, uma interrogação. Alguém que leu o material parece ter-se surpreendido com a ingenuidade das observações do agente. ${ }^{37}$

Foi constante esse acompanhamento dos órgãos repressores. Em outro ofício da Pide, ao governador de Lisboa, datado de 19 de outubro de 1959, vemos a seguinte informação: "dada a suspeita política que recai sobre a grande maioria dos seus associados e, nomeadamente, sobre os membros que compõem a direção, vêm sendo, na medida do possível, controladas por esta Polícia as atividades do referido Club". 38

Nesse ano, a Pide, além de perseguir sistematicamente alguns membros do CMA, já havia fechado sua sede e apreendido arquivos e documentação. Por esse motivo, mas também em função da constante mobilidade dos marítimos e da fuga de algumas de suas lideranças, que saíram de Portugal e passaram a se engajar mais ativamente nas lutas anticoloniais, o clube encerrou suas atividades.

Em 1958, o CMA já apresentava dificuldades para sua manutenção. Uma assembleia, realizada em 19 de janeiro desse ano, no Clube Desportivo da Graça, designou uma comissão diretiva para reorganizar as atividades e tentar resolver "a situação extraordinariamente crítica”. Os responsáveis informaram que pretendiam o quanto antes voltar a oferecer excursões, jogos de futebol e consultas médicas. Pelo Informe no 43, de 20 de janeiro de 1958, do agente Fernando Palma, ficamos sabendo que compareceram à reunião 37 pessoas, "quase todos negros, somente dois homens e cinco mulheres brancas" ${ }^{39} \mathrm{O}$ fôlego da retomada das atividades seria de curta duração, mas seu exemplo de ação permaneceria. Nas palavras de Tomás:

37 ANTT, PIDE/DGS, Serviços Centrais, Proc. n 2.668/1954, Clube Marítimo Africano, fls. 596-597. 38 ANTT, PIDE/DGS, Serviços Centrais, Proc. n 2.668/1954, Clube Marítimo Africano, fl. 547. 39 ANTT, PIDE/DGS, Serviços Centrais, Proc. n 2.668/1954, Clube Marítimo Africano, fls. 569-570. 
O Clube Marítimo haveria de servir de modelo para futuras atividades políticas. O Estado Novo, restringindo as liberdades individuais, proibia a formação de sindicatos e associações, mas tolerava as agremiações de caráter desportivo e cultural. Daí terem estes jovens africanos pensado na possibilidade de desenvolverem atividades ilegais no quadro de organismos reconhecidos pelo regime. ${ }^{40}$

Enfim, apresentando-se como um clube desportivo e recreativo, disposto a levar cultura para seus associados, ocupando os espaços menos vigiados pelo regime, o CMA desenvolveu, em paralelo, uma importante atividade de conscientização, construindo alternativas de combate ao colonialismo português, inclusive por exercer um papel importante no estabelecimento e na manutenção dos contatos entre os dois eixos da ação nativista: os estudantes africanos que estavam na metrópole e os militantes da luta pela independência que permaneceram nas províncias/colônias.

O encerramento das atividades do CMA seria o primeiro de uma série de acontecimentos que marcaria o fim de uma etapa da luta anticolonial caracterizada pela ação conjunta de jovens africanos das diferentes colônias portuguesas. A fase seguinte seria marcadamente nacional, com o início das guerras de libertação.

\section{O controle dos clubes esportivos: o caso de Angola}

Em Angola, desde o século XIX existia uma sensível relação entre a prática esportiva e as questões políticas locais. ${ }^{41}$ Vale lembrar que, já em 1922, muitas agremiações foram fechadas por Norton Matos, por suspeitas de envolvimento com movimentos autonomistas. ${ }^{42} \mathrm{Na}$ década de 1960, em virtude do início dos conflitos armados, tornou-se mais aparente a associação esporte-política. Com isso, progressivamente aumentaram as desconfianças com os clubes. ${ }^{43}$

40 TOMÁS, António. O fazedor de utopias - uma biografia de Amílcar Cabral. Praia: Spleen Edições, 2008. p. 71.

41 Para mais informações, ver MARZANO, Andrea. Práticas esportivas e expansão colonial em Luanda. In: MELO, Victor Andrade de; BITTENCOURT, Marcelo; NASCIMENTO, Augusto (Orgs.). Mais do que um jogo: o esporte no continente africano. Rio de Janeiro: Apicuri, 2010. p. 71-99.

42 Para mais informações, ver BITTENCOURT. Op. cit., 1999.

43 Estima-se que, às vésperas da independência, Angola possuía 144 clubes esportivos, que somavam mais de 63 mil sócios. Para mais informações, ver FONSECA, Ana Sofia. Angola, terra prometida - a vida que os portugueses deixaram. Lisboa: Esfera dos Livros, 2009. 
Merece destaque o caso do Clube Atlético de Luanda. Fundado em 1924, em 1961 recebeu a alcunha de "clube dos terroristas", pelo fato de por ele terem passado, como atletas ou dirigentes, alguns dos que iriam levar adiante a luta armada anticolonial. ${ }^{44} \mathrm{O}$ apelido certamente alcançara os ouvidos da Pide (seria o caso de admitir a possibilidade de ter sido cunhado por seus próprios agentes), fazendo com que aquela polícia tenha se tornado mais alerta ao que se passava no âmbito esportivo.

O órgão de segurança aumentou a pressão sobre as agremiações, inclusive sobre as menores, as de bairro, que não participavam dos campeonatos da colônia/província, como era o caso do Botafogo ${ }^{45}$ que na área esportiva dedicava-se quase integralmente ao futebol, oferecendo ainda a seus sócios um serviço gratuito de consultas médicas e um curso de alfabetização. O clube possuía também um departamento cultural que publicava um pequeno jornal.

Localizado na periferia de Luanda, o Botafogo tornou-se um ponto de encontro de pessoas de diferentes gerações e regiões de Angola; para alguns de seus adeptos, tratava-se de um espaço de conscientização política e realização de trabalho clandestino. Por tal perfil, em 1961, seria fechado, e alguns de seus dirigentes, presos, sob o argumento de que atuavam em organizações clandestinas. ${ }^{46}$

As investigações passaram a ser constantes. Por exemplo, os clubes deveriam submeter os nomes de suas diretorias eleitas à aprovação da autoridade governamental local, normalmente o governador, que antes de se posicionar consultava o Conselho Provincial de Educação Física ${ }^{47}$ e a Pide.

No Arquivo Nacional da Torre do Tombo, no fundo da Pide/DGS, foi possível consultar milhares de processos relacionados com agremiações esportivas de Angola, o que permite conhecer em detalhes como o controle foi exercido. Percebe-se que foram investigados todos os clubes da colônia/província, o que implica dizer que negros, mestiços e brancos passavam pelo crivo moral e político da Pide. A principal documentação a que tivemos acesso são os pareceres

44 FERREIRA, Luís Alberto. História do Club Atlético de Loanda. Primeiro volume - 1924-1953. Subsídios para a história do desporto angolano. Luanda: Edição do Club Atlético de Luanda e Saudade, 2008.

$45 \mathrm{O}$ nome era inspirado no clube do Rio de Janeiro (Botafogo Futebol e Regatas).

46 BITTENCOURT. Op. cit., 1999.

47 Órgão ligado à Secretaria Provincial de Educação, instalado em cada uma das províncias portuguesas. 
daquela polícia sobre os nomes eleitos para as diretorias dos clubes esportivos, posteriormente enviados às demais instâncias governamentais. Atenção maior era dada aos casos em que era identificado um manifesto desejo de independência ou de contestação do regime.

Há casos de aprovação integral por parte da Pide dos componentes da diretoria sem nenhuma ou com pequenas observações. Estas podiam ser de natureza política, como vemos no Ofício $n^{\circ} 2.328 / 1965$, que trata da avaliação do corpo dirigente do Sporting Clube de Benguela, apontando-se apenas um indivíduo que no "campo político, embora não haja fatos palpáveis, é suspeito de alimentar ideias separatistas". ${ }^{48}$ Ou de natureza moral, como vemos no Ofício n 2.333/1965 a avaliação do Clube Recreativo e Beneficente do Bocoio, indicando que um dos diretores abusava no consumo de álcool. ${ }^{49}$

É possível observar reprovações de nomes sem maiores explicações. Esse é o caso do Ofício no 2.332/1965, que não aprovou José Joaquim Diogo Branco, Etardo Alberto Palhares Costa e Manuel da Silva Antunes para a direção do Sport Club Portugal..$^{50}$ Reprovações por razões políticas também são corriqueiras, enquanto as restrições de caráter moral parecem ser menos determinantes no veto.

Quanto às observações de natureza política, iam desde um leve "demonstra tendências separatistas", passando por ações mais concretas, como ter apoiado a candidatura de Humberto Delgado à presidência de Portugal, ${ }^{51}$ chegando até a denúncia de envolvimento explícito com atividades de contestação. Entre as acusações mais graves estava a de defender a independência de Angola ou a de ter demonstrado sentimentos "antiportugueses". Do ponto de vista moral, eram levantados casos de homossexualidade, adultério, desonestidades diversas, existência de dívidas, problemas com a polícia e com a justiça. A documentação não deixa dúvida: a vida privada e pública era esquadrinhada.

48 ANTT, PIDE/DGS, Delegação de Angola, Clubes e Associações, Proc. n 15.03-A, Ofício nº 2.328/1965, fls. 23-50.

49 ANTT, PIDE/DGS, Delegação de Angola, Clubes e Associações, Proc. n 15.03-A, Ofício nº 2.333/1965, fl. 51 .

50 ANTT, PIDE/DGS, Delegação de Angola, Clubes e Associações, Proc. n 15.03-A, Ofício nº 2.332/1965, fl. 1 .

51 Para mais informações sobre a campanha de Humberto Delgado, inclusive sua importância e repercussão nas províncias, especialmente em Angola, ver PIMENTA. Op. cit. 
Por vezes, a avaliação na instância governamental era mais complacente. Como é possível perceber no Ofício no 2.701/1966, apesar de Luís Vasconcelos Câmara Pires, eleito para a diretoria do Sport Novo Redondo e Benfica, ser qualificado pela Pide como oposicionista ao regime, ${ }^{52}$ seu nome é homologado. $\mathrm{O}$ mesmo pode ser visto no Ofício n ${ }^{\circ}$ 5.673/1967: apesar de sobre determinado postulante ter-se apurado "que vive em regime de mancebia" com uma "nacional", apresentada como uma ex-empregada de uma boate, isso não afetou sua homologação. Nesse último caso, a documentação deixa claro que o indivíduo referido não tinha qualquer problema político. ${ }^{53}$

Houve casos em que as investigações foram mais rigorosas e minuciosas. Por exemplo, o ofício de Fernando Alberto Ramalho Moutinho, chefe da subdelegação da Pide de Carmona (atual Uíge), datado de 25 de março de 1964, comentando as eleições para o Clube Recreativo do Uíge, infere que Teófilo Pereira de Sousa, supostamente opositor do regime, teria tentado eleger-se graças à manobra de Raul Jorge Gonçalves Figueiredo, "objeto de intensa vigilância”:

Continuará esta subdelegação com a máxima atenção a esse grupo (já era o mesmo do cineclube que "morreu") solicitando que V.Exa. se digne ordenar que seja remetido a esta dependência o que consta a respeito do chefe de produção da Rádio Clube do Congo Português, que parece ter estado bastante tempo em Benguela, Elísio de Lacerda (fl. 258). ${ }^{54}$

Como vimos no caso do Atlético de Luanda e do Botafogo, algumas agremiações eram consideradas mais suspeitas. Por exemplo, em ofício de 9 de setembro de 1967, que tratava da diretoria do Clube Atlético Lobito, a Pide relacionou alguns nomes que, segundo a investigação, estariam ligados ao Movimento Popular de Libertação de Angola (MPLA): Manuel Carlos da Piedade, Augusto Reis Françony, Antônio Domingos Pitra e Hermano Gonçalves da Costa. O documento observa ainda que, dos 21 dirigentes, apenas três são europeus, dos quais dois "não merecem confiança”. As reuniões são apresentadas como relativamente secretas, sendo impedida a participação de Carlos Alberto de Oliveira Pereira,

52 ANTT, PIDE/DGS, Delegação de Angola, Clubes e Associações, Proc. n 15.03-D, Ofício nº 2.701/1966, fl. 366 .

53 ANTT, PIDE/DGS, Delegação de Angola, Clubes e Associações, Proc. n 15.03-G, Ofício nº 5.673/1967, fl. 35 .

54 ANTT, PIDE/DGS, Delegação de Angola, Clubes e Associações, Proc. nº 15.03-A, ofício de 25 de março de 1964, fls. 255-258. 
que os demais identificaram como colaborador do regime. Por fim, a acusação mais dura, de que o grupo parece propagar sentimentos antiportugueses:

o clube é frequentado quase exclusivamente por africanos que, vendo-se isolados dos europeus, não só nas reuniões que têm por fim tratar assuntos de interesse do mesmo, como naquelas que todas as noites ali podem efetuar e nas quais à vontade podem tratar problemas de caráter político-subversivo, sem que qualquer pessoa afeita ao regime possa tomar conhecimento (fls. 179-180). ${ }^{55}$

O clima de constante suspeita em certa medida desencadeou até mesmo temores exagerados em algumas agremiações, até porque os julgamentos nem sempre guardavam grande coerência, sendo comuns as divergências entre os responsáveis pelas investigações. Por exemplo, o Club Beneficente e Recreativo do Cubal enviou uma carta à Pide perguntando se haveria algum inconveniente em convidar para uma conferência o médico José Carolino Serrado da Fonseca Santos.

Dando prosseguimento aos trâmites burocráticos, a subdelegação da Pide do Lobito encaminhou uma consulta ao subdiretor geral, informando que estranhara o fato de o presidente do clube ter afirmado que não conhecia o médico, "tanto mais que um e outro são sobejamente conhecidos desta Polícia como oposicionistas e até professando ideias separatistas" (ofício de 3 de junho de 1965). A subdireção, contudo, respondeu que a Pide não tinha de se pronunciar, sendo de inteira responsabilidade da agremiação a atividade prevista. Sugeria, no entanto, que se apurasse quem havia indicado o nome de José Carolino como conferencista (29 de junho de 1965). ${ }^{56}$

Processo semelhante de controle dos clubes desportivos, por parte da Pide, pode ser identificado em Moçambique e Guiné-Bissau. Já em Cabo Verde, as tensões foram de distintas ordens e assumiram contornos diferentes, provavelmente por não haver conflitos bélicos no território e por historicamente haver uma relação mais forte de lealdade à metrópole. ${ }^{57}$ Ainda assim, pode-se perceber um

55 ANTT, PIDE/DGS, Delegação de Angola, Clubes e Associações, Proc. no 15.03-H, Ofício nº 6.060, de 9 de setembro de 1967, fls. 170-184.

56 ANTT, PIDE/DGS, Delegação de Angola, Clubes e Associações, Proc. n 15.03-B, Ofício n 516, de 3 de junho de 1965, fl. 142, e Ofício no 3.068, de 29 de junho de 1965, fl. 141.

57 Para mais informações sobre a relação de Cabo Verde com a metrópole, ver FERNANDES, Gabriel. Em busca da nação: notas para uma reinterpretação do Cabo Verde crioulo. Florianópolis/ Praia: UFSC/Instituto da Biblioteca Nacional e do Livro, 2006. 
maior cuidado com o funcionamento das agremiações esportivas desde que Salazar assumiu a direção do Conselho de Ministros. Vejamos o caso cabo-verdiano.

\section{O controle dos clubes esportivos: o caso de Cabo Verde}

No Fundo da Repartição Provincial do Arquivo Histórico Nacional de Cabo Verde (AHNCV), encontramos, enviados à administração governamental, muitos pedidos de aprovação dos nomes que compunham as diretorias e/ou dos estatutos de clubes. Se tal procedimento era obrigatório desde o século XIX, ampliara-se o rigor com o decorrer do tempo. No final da década de 1930, os dirigentes eleitos, por exemplo, passaram a ter que assinar documentos como estes:

Nos termos do artigo $3^{\circ}$ da lei $n^{\circ} 1910$ de 21 de maio de 1935, declaro pela minha honra, que não pertenço nem jamais pertencerei a associações ou institutos secretos definidos no artigo $5^{\circ}$ da lei acima mencionada. ${ }^{58}$

Declaro por minha honra que estou integrado na ordem social estabelecida pela constituição política de 1933, com ativo repudio do comunismo e de todas as ideias subversivas. ${ }^{59}$

Os clubes eram inspecionados de múltiplas formas. As tensões eram constantes. Vejamos a carta que Felisberto Nunes de Almeida, administrador do Conselho de Praia, enviou, em 29 de julho de 1939, para Amilcar Carvalhal, dirigente de uma agremiação:

Tendo-me constado que V.Exa. pretende realizar hoje uma reunião da assembleia (geral) do grupo (desportivo) Luzitânia, queira ter a bondade de suspender qualquer medida que para tal fim tenha tomado, e comparecer no meu gabinete no dia 31 do corrente pelas 15 horas e 30 minutos. ${ }^{60}$

Essa convocatória é ainda posteriormente reforçada:

Rogo a V.Exa. se digne comparecer no meu gabinete no dia 31 do corrente pelas 15 horas e 30 minutos, devendo V.Exa. fazer-se acompanhar dos restantes membros da

58 AHNCV, Fundo da Repartição Provincial dos Serviços da Administração Civil (1907-1979), SC:CISR: (A, B, C, D, E, F).

59 AHNCV, Fundo da Repartição Provincial dos Serviços da Administração Civil (1907-1979), SC:CISR: (A, B, C, D, E, F).

60 AHNCV, Fundo da Repartição Provincial dos Serviços da Administração Civil (1907-1979), SC:CISR: (A, B, C, D, E, F). 
direção, do conselho fiscal, da mesa da Assembleia Geral e ainda dos 3 sócios em que a direção, em 28 de novembro de 1938, delegou a administração do grupo. ${ }^{61}$

O problema, nesse caso, era o clube ter eleito um novo corpo dirigente e convocado uma reunião de sócios sem a anuência da administração colonial, algo que feria a legislação em vigor.

Por vezes, os conflitos dessa natureza duravam meses, como podemos observar nas tensões estabelecidas, nos anos 1947 e 1948, entre o presidente da Associação Desportiva de Sotavento (ADS), Orlando Luiz de Oliveira, e o administrador do Conselho de Praia, Antônio Policarpo Sousa Santos. O grupo intentava organizar uma quermesse e sofreu reprimenda por descumprir a legislação. Vejamos o ofício de setembro de 1947:

Cumpre-me elucidar V. Exa. que a quermesse que essa associação pretende levar a efeito tornou-se pública [...]. Não tem V. Exa. que lastimar a forma como o assunto chegou ao meu conhecimento, porquanto sou obrigado, por lei expressa, a conhecer tudo o que se passe na área sob minha jurisdição e não vim aprender a ser administrador nesta colônia, porque exerço essas funções há quinze anos. Conheço perfeitamente a autoridade que me confere a lei e não desconheço a forma de a exercer e de a fazer respeitar, se para tanto for necessário. ${ }^{62}$

Na verdade, o embate se estabeleceu porque a administração também pretendia organizar uma festividade em data semelhante. A ADS contestou que marcara sua atividade anteriormente e provocou Antônio Policarpo, afirmando que ele também não pedira autorização, o que o deixou indignado:

eu procurei ser calmo ao ler a nota a que estou respondendo e a portaria 1686, onde nada encontro que me obrigue a pedir autorização a essa Associação para a realização do meu projeto, que tem o fim de assistência aos necessitados deste Conselho. Nem se pode admitir que o Governo legislasse subordinando uma autoridade a uma associação desportiva. O contrário seria de lastimar, mas não é como V. Exa. pretende. ${ }^{63}$

61 AHNCV, Fundo da Repartição Provincial dos Serviços da Administração Civil (1907-1979), SC:CISR: (A, B, C, D, E, F).

62 AHNCV, Fundo da Repartição Provincial dos Serviços da Administração Civil (1907-1979), SC:CISR: (A, B, C, D, E, F).

63 AHNCV, Fundo da Repartição Provincial dos Serviços da Administração Civil (1907-1979), SC:CISR: (A, B, C, D, E, F). 
A partir daí, parece ter ficado mais difícil a relação entre ambos. Em dezembro de 1947, Antônio Policarpo envia nova carta à ADS: "Peço V.Exa. o favor de me mandar informar quem foi que autorizou a realização do desafio de futebol que teve lugar no último domingo 7 do corrente." Jorge Santos, secretário da associação, responde remetendo a quantia de Esc. $10 \$ 00$ referente à multa por ter realizado sem autorização a partida entre o Boavista e o Vitória.

Antônio Policarpo não baixa a guarda; parecendo ainda mais ofendido, afirma: "não posso deixar de chamar a atenção dessa associação para o fato de ter enviado a quantia referente ao jogo depois deste realizado, sem o cumprimento do que se encontra expressamente determinado por quem de direito e ainda como era costume anteriormente". A ADS, a princípio, simplesmente contesta que pagou a multa prevista em lei, mas depois envia mais explicações e pedidos de desculpas.

Em carta de 15 de dezembro de 1947, o administrador responde que acolhe as explicações, diz que não tem razão para não acreditar nas boas intenções da ADS, pede que se cumpra a lei e conclui: "não tenho qualquer má vontade contra essa associação, mas não abdico da autoridade que a lei me confere e que tenho de prestigiar".

A despeito dessa manifestação de aparente boa vontade, em 14 de fevereiro de 1948, Antônio Policarpo envia outra mensagem à ADS:

Lamento ter de informar V.Exa. que o desafio de futebol projetado para amanhã no campo dessa associação, não pode ter lugar, visto o programa não ter sido submetido como é de lei e já por várias vezes tenha chamado a atenção dessa associação à aprovação prévia desta administração.

De fato, no caso cabo-verdiano, esses conflitos não eram desencadeados, como no caso angolano na década de 1960, por posturas antinacionais, ainda que fossem, em sentido distinto, anticoloniais. Isto é, não eram iniciativas relacionadas com movimentos em favor da independência, mas, sim, uma reação ao excesso de intervenção da metrópole nas questões locais, algo que incomodava profundamente as elites cabo-verdianas, que exigiam maior autonomia e respeito às peculiaridades da colônia.

Vejamos que Antônio Policarpo chegou mesmo a ser considerado um entusiasta do esporte. Segundo informa Aristides Pereira: 
era um indivíduo controvertido, que se aclimatou depressa, praticamente ele passou a conhecer toda juventude de Praia. Nos desafios de futebol, ele ia e gostava, fazendo claque pelo clube que ele gostasse mais [...]. Extremamente popular aqui e, nessa questão do desporto, o fraco dele era o Boavista. ${ }^{64}$

Pereira lembra que quando o Boavista, do qual fazia parte da direção, resolveu fazer um quadrangular para homenagear o administrador, que se despedia da província, foi chamado pela polícia para explicar o porquê do evento. Segundo a memória de Aristides, estas teriam sido as palavras do comissário:

Lá que vocês façam um jantar, muito bem, num recinto fechado, não há problemas. Mas se vocês se atrevem a fazer uma manifestação pública!... [...] ou vocês acabam com essa história de futebol já, ou então eu posso ir lá e acabar com isso tudo. E, digo-lhe mais, por muito menos está muita gente no Tarrafal. ${ }^{65}$

Mesmo considerando que pode haver algum exagero nesse posicionamento, uma mobilização de memória reforçando o aspecto da repressão, trata-se de mais um indicador de que havia certo grau de tensão ao redor da organização de eventos esportivos no arquipélago.

Em Cabo Verde, os maiores problemas parecem ter sido mesmo de ordem diversa. Vejamos alguns exemplos. Quando interpelado por irregularidades, em carta de 21 de maio de 1951, o secretário da ADS responde que nunca regularizara os estatutos da associação por problemas financeiros, inclusive porque as agremiações tinham de pagar os custos do processo, até mesmo uma taxa para a publicação do documento no Boletim da Província. Aproveita para criticar o governo, sugerindo que as dificuldades se devem à falta de incentivo ao desenvolvimento do esporte. ${ }^{66}$

Orlando Morazzo, em nome da administração, responde dizendo que o problema é mais grave: os estatutos sequer poderiam ser apreciados por não

64 PEREIRA, Aristides. O meu testemunho - uma luta, um partido, dois países. Lisboa: Editorial Notícias, 2003.p. 359. Aristides Pereira foi presidente da República de Cabo Verde de 1975 até 1991. 65 Ibid., p. 359.

66 AHNCV, Fundo da Repartição Provincial dos Serviços da Administração Civil (1907-1979), SC:CISR: (A, B, C, D, E, F). 
cumprirem os termos legais. ${ }^{67}$ A divergência, de fato, se dava porque a ADS relutava em cumprir na íntegra o que determinava o governo provincial.

Dadas as discordâncias constantes, em 1955, o governador Manuel Marques de Abrantes Amaral chegou a promover uma intervenção na ADS, nomeando uma comissão administrativa. A motivação principal foi garantir a organização das atividades esportivas que fariam parte do programa de recepção ao presidente de Portugal, Craveiro Lopes em sua visita ao arquipélago.

Houve também muitas divergências das autoridades coloniais com a Associação Desportiva de Barlavento (ADB), que, da mesma forma que a ADS, passou por dificuldades financeiras. O relatório de Mota Carmo, administrador do Conselho de São Vicente, de 17 de setembro de 1945, já informava que as agremiações da Ilha tinham grandes dívidas, mantendo-se graças a apoios individuais (por ele chamados de carolas). Para ele, até mesmo o fato de existirem muitos clubes contribuía para tais problemas, como podemos ver pelo ofício datado de 4 de março de 1948, enviado ao chefe da Repartição Central dos Serviços da Administração Civil, prestando contas de sua análise dos documentos e livros de contas dos grupos esportivos de Mindelo. ${ }^{68}$

A administração provincial, contudo, nem sempre parece ter seguido os mesmos rígidos critérios. Vejamos um exemplo. Identificamos uma carta, de dezembro de 1957, do presidente do The St. Vicent Cape Verde Island Golf and Lawn Tennis Club, uma agremiação fundada por ingleses em Mindelo, em 1933, solicitando que fossem aceitas mudanças em seus estatutos, para que não britânicos pudessem ser aceitos como sócios.

Uma breve nota manuscrita afixada à carta dá conta da decisão da administração: "Foi mandado arquivar sem se mandar ao Conselho de Educação Física, em virtude de ser uma situação irregular, que não podia merecer deferimento. Mas quase seria um incidente diplomático, tão antigo é o clube." A autoridade colonial reconhece que o funcionamento da agremiação fora autorizado por uma portaria, mas observa que não houve o ajuste necessário em função das bases

67 AHNCV, Fundo da Repartição Provincial dos Serviços da Administração Civil (1907-1979), SC:CISR: (A, B, C, D, E, F).

68 AHNCV, Fundo da Repartição Provincial dos Serviços da Administração Civil (1907-1979), SC:CISR: (A, B, C, D, E, F). 
legais posteriores, tendo-se mantido, mesmo de forma ilegal, a ideia original de que eram aceitos como sócios somente britânicos residentes em São Vicente.

Ao fim, já em 1969, incentivadas pela administração colonial, dando origem ao Clube Anglo-Português de Golfe de São Vicente, fundiram-se a agremiação dos ingleses e outra dos cabo-verdianos que fora fundada em 1940, o Clube de Golfe de São Vicente. Isso causou surpresa em algumas lideranças esportivas da Ilha, que reconheciam as profundas diferenças entre os clubes. ${ }^{69}$

No período de acirramento dos conflitos coloniais em Angola, Moçambique e Guiné, com caráter mais explícito de contestação, em Cabo Verde só encontramos duas experiências que envolveram o lazer e lateralmente o esporte. Uma delas foi liderada por Abílio Duarte, no final dos anos 1950; tratou-se de uma iniciativa de conscientização política por meio de atividades culturais, chamada de Grupo do $3^{\circ}$ Ciclo, por estar ligado aos estudantes do Liceu Gil Eanes, de Mindelo.

Como se pode ver no livro de Aristides Pereira, alguns militantes reconhecem a importância dessa iniciativa. Humberto Bettencourt Santos sugere até mesmo que um dos motivos para a criação do Grupo foi o aumento do controle sob as associações esportivas:

Foi uma forma de introduzir novos dados na nossa mentalidade. [...]. Até proibiram Cabo Verde de participar nos jogos de futebol que se faziam antigamente com o Senegal, a Guiné etc. A partir das independências na África Ocidental, Cabo Verde já nem podia participar nesse tipo de manifestação desportiva. ${ }^{70}$

A segunda experiência foi liderada por Carlos Reis, militante do na época clandestino Partido Africano para Independência da Guiné e Cabo Verde. Segundo informa, quando retornou a Cabo Verde, em 1965, envolveu-se com a dinamização do Clube Benfica de Assomada, procurando reunir os jovens em um grupo de teatro, que montou duas peças, "em crioulo e procurando sempre denegrir a Administração Colonial [...] contribuindo para aumentar o descontentamento do povo". ${ }^{71}$

69 Em 1975, com a independência, a agremiação voltou a se chamar Clube de Golfe de São Vicente, ativo até os dias de hoje. Para mais informações, ver MELO, 2011.

70 Apud PEREIRA. Op. cit., p. 351. Sobre as excursões de equipes de Cabo Verde a outros países africanos, ver MELO. Op. cit., 2001.

71 Ibid., p. 424. 
Enfim, o quadro de associação entre o esporte e a política no caso cabo-verdiano foi bastante distinto do angolano, também refletindo outra postura em relação à presença colonial, que podemos identificar como anticolonial, ainda que não pró-independência. De toda maneira, também no arquipélago houve tensões e iniciativas de controle das associações esportivas.

\section{Conclusão}

Não devemos crer que o esporte carregue um dom imanente de estabelecer a contestação, da mesma forma que não o tem de manipular ou estabelecer o controle. $\mathrm{Na}$ análise do fenômeno, parece prudente tomar alguns cuidados: perceber o quanto as agremiações esportivas foram mesmo utilizadas como alternativas políticas, prospectando com acuidade se determinadas posições contemporâneas não exacerbam essa compreensão por construir uma narrativa heroica sobre o passado; não desprezar o fato de que grande parte dos que se envolveram com os clubes estava mesmo prioritariamente interessada na diversão oferecida; considerar que, mesmo para os que tinham uma intencionalidade política clara, o aspecto do divertimento era também importante; ter em conta que interpretações lineares ou diametrais (que reproduzem o modelo "dominação ou subversão") pecam por não captar o objeto em sua complexidade.

De qualquer forma, tendo em conta os casos que discutimos neste artigo, parece-nos possível afirmar que esse tipo de estratégia menos claramente identificada como política merece atenção por ter ajudado na consolidação de certas iniciativas de contestação, tanto por atrair novos militantes quanto por gestar espaços mais confortáveis de organização dos grupos opositores ao regime, inclusive por permitir uma maior atuação de certas lideranças das lutas anticoloniais.

Parece evidente que o início da luta armada em Angola, em 1961, mudaria o cenário das associações culturais e esportivas em todas as colônias portuguesas na África. As tentações de controle por parte do regime colonial seriam exacerbadas, e a margem sutil de organização e conscientização da juventude africana, existente no campo esportivo, tenderia a se fechar. O caso angolano ilustra bem essa nova atenção das forças de repressão com o esporte, que pode ser percebida também nas demais colônias africanas de Portugal. 